\title{
The potential use of histone deacetylase inhibitors in the treatment of depression
}

Manabu Fuchikami ${ }^{1)}$, Shigeto Yamamoto ${ }^{1)}$, Shigeru Morinobu ${ }^{2)}$, Satoshi Okada ${ }^{1)}$, Yosuke Yamawaki ${ }^{3)}$, Shigeto Yamawaki ${ }^{1)}$

*Corresponding author:e-mail: smorinob@kochi-u.ac.jp

1) Department of Psychiatry and Neurosciences, Applied Life Sciences Institute of Biomedical \& Health Sciences, Hiroshima University, 1-2-3 Kasumi, Minami-ku, Hiroshima, Hiroshima, Japan TEL: +81-82-257-5555; FAX: +81-82-257-5209

2) Department of Neuropsychiatry, Kochi Medical School, Kochi University Kohasu Oko-cho, Nankoku, Kochi 783-8505, Japan

3) Department of Cellular and Molecular Pharmacology, Institute of Biomedical and Health Sciences, Hiroshima University, 1-2-3 Kasumi, Minami-ku, Hiroshima, Hiroshima, Japan.

Acknowledgements of funding and grants: This work was supported by Grant-in-Aid for General Scientific Research, and Scientific Research on Innovative Areas from the Ministry of Education, Science, and Culture of Japan, a Health Science Research Grant for Research on Brain Science from the Ministry of Health and Welfare of Japan, and a grant from Core Research for Evolutional Science and Technology (CREST) of Japan Science and Technology Agency (JST) and a Grant-in-Aid for 'Integrated research on neuropsychiatric disorders' carried out under the Strategic Research Program for Brain Sciences by the Ministry of Education, Culture, Sports, Science and Technology (MEXT). 


\section{Introduction}

Major depression was ranked first among 10 leading diseases with respect to global disease burden in high-income countries in 2001 as indicated by a systematic analyses of population health data, and it accounted for the third-highest number of disability-adjusted life years (Lopez et al., 2006). Although different types of antidepressants including selective serotonin reuptake inhibitors (SSRIs), serotonin noradrenaline reuptake inhibitors (SNRIs), bupropion, and mirtazapine, have been developed and used clinically, a certain percentage of patients with depression do not show an adequate response to these newer antidepressants or to tricyclic antidepressants.

Results from the Sequenced Treatment Alternatives to Review Depression (STAR*D) study demonstrated that almost $35 \%$ of 3671 patients with nonpsychotic major depressive disorder did not achieve remission, despite undergoing 1 to 4 successive treatment steps during which 6 different types of antidepressants (SSRI, SNRI, tricyclic antidepressant, bupropion, mirtazapine, and monoamine amine oxidase inhibitor) were administered (Rush et al. , 2006). Similarly, the Combining Medications to Enhance Depression Outcomes (CO-MED) study showed that the remission rate of a 12-week combination treatment with the 2 different types of antidepressants including 
bupropion, mirtazapine, citalopram, and venlafaxine, was approximately $40 \%$ among patients with major depression (Rush et al.-, 2011). Given the limited efficacy of antidepressants, the use of aripiprazol to augment antidepressant therapy is approved by the U.S. Food and Drug Administration (FDA) for patients with antidepressant-resistant depression. In addition, electroconvulsive treatment is often selected in the treatment of drug-resistant depression in Japan. Given that there exists such a large percentage of depressed patients who are drug-resistant, a new class of antidepressants with mechanisms distinct from the regulation of monoaminergic signal transduction is required.

Preclinical studies on the pathophysiology of depression suggest that changes in gene expression, such as brain-derived neurotrophic factor (BDNF) (Duman et al., 1997; Nestler 2002), glial cell line-derived neurotrophic factor (GDNF) (Hisaoka et al., 2001; Uchida et al., 2011), and vascular endothelial growth factor (VEGF) (Greene et al., 2009), in the brain may be closely involved in the development of depression. With respect to gene transcription, recent epigenetic studies show that the regulation of chromatin structure by both histone modifications and DNA methylation plays an important role (Ashraf et al., 1998; Lieb and Clarke, 2005; Verdin and Ott, 2014). In fact, while valproic acid (VPA), a histone deacetylase inhibitor, has a long history of use 
in the treatment of bipolar disorder as a mood stabilizer (Phiel et al., 2001), VPA was reported to increase the activity of BDNF promoter IV and the level of exon IV-containing BDNF mRNA (Yasuda et al., 2009). In this paper, we review the efficacy of HDAC inhibitors as antidepressants based on evidence from the rodent studies, and discuss the clinical potential of HDAC inhibitors for the treatment of depression.

\section{Transcriptional regulation by histone deacetylase inhibitors}

Numerous preclinical studies postulate that the effect of antidepressants requires alterations in central signal transduction mediated by gene transcription (Myers and Davis, 2002). Transcription is regulated by the concerted action of transcription factors and cofactors that modify and remodel the structure of chromatin (Holliday, 2006). Thus, a clear understanding of the epigenetic mechanisms of depressive symptoms and associated alterations in gene expression may provide opportunities for the development of novel therapies. Histone acetylation, which alters the compact chromatin structure and changes the accessibility of DNA to transcriptional factor proteins, is emerging as a fundamental mechanism for regulating gene expression (Goldberg et al., 2007, Kurdistani and Grunstein, 2003).

Histone acetylation is regulated by the opposing activities of histone 
acetyltransferases (HATs) and HDACs (Kramer et al. , 2001). These enzymes maintain the equilibrium of acetyl groups added to or from histone protein, mainly $\mathrm{H} 3$ and $\mathrm{H} 4$. Activation of HAT facilitates the binding of acetyl groups to histone protein and subsequently increases the acetylation levels of histone in the nucleus. In contrast, activation of HDAC catalyzes the removal of acetyl groups from histone protein, and subsequently decreases histone acetylation. In this context, administration of an HDAC inhibitor prevents the decrease in histone acetylation, leading to sustained activation of gene transcription.

To date, 18 different HDACs are known in humans, and these enzymes are classified into 2 families and 4 classes (Khochbin et al., 2001). The 2 families are the classical zinc-dependent family and the silent information regulator 2-related protein (SIRT) family, which are nicotinamide-adenine-dinucleotide (NAD)-dependent. The classical HDACs are very similar in structure and divided into 4 classes: class I (HDACs 1, 2, 3, 8), class IIa (HDACs 4, 5, 7, 9), class IIb (HDACs 6, 10), and class IV (HDAC11) (Walkinshaw and Yang XJ, 2008). The class I HDACs are found mostly within the nucleus and are expressed ubiquitously, whereas class II members shuttle between the nucleus and cytoplasm (Gibson and Murphy 2010), with the exception of HDAC6, which are located only in the cytoplasm. Class IV HDAC, HDAC11, is 
structurally different from class I and class II HDACs. On the other hand, the class III SIRT gene family consists of 7 isoforms in human (Grozinger et al., 2001). SIRTs 1, 2, 6, and 7 are found in the nucleus, whereas SIRTs 3, 4, and 5 are found in the mitochondria (Han, 2009; Michishita et al., 2005). In addition, the HDACs are expressed in a cell and tissue-specific manner. For instances, class I, II, and IV HDACs are expressed primarily in neurons (Broide et al., 2007). While the expression levels of HDACs 2, 3, 4, 5, 11 are relatively high in oligodendrocytes (Gräff, and Tsai, 2013), the expression of most SIRTs is higher in fetal brain compared to adult brain (Michishita et al., 2005).

HDAC inhibitors are divided into groups based on their chemical structure, including hydroxamic acids, carboxylic acids, aminobenzamides, cyclic peptides, epoxyketones, and hybrid molecules (Grayson et al., 2010; West and Johnstone, 2014). Extensive studies examining the specific target enzymes of HDAC inhibitors have been undertaken. For example, vorinostat (SAHA), a hypoxamate-based inhibitor, acts on HDAC1, 2, 3, 4, and 8; MS-275, a bezamide-based inhibitors, acts on HDAC 1, 2, 3, and 9. Romidepsin, a cyclic peptide-based inhibitors, acts on HDAC1 and 2. The development of isozyme-selective HDAC inhibitors may be an important mean by which to achieve enhanced therapeutic efficacy and reduced toxicity.

If global reduction in gene expression in certain brain regions, such as the 
hippocampus and prefrontal cortex, in response to stress is involved in the pathophysiology of depression, then chronic but not acute treatment with an HDAC inhibitor could antagonize the decrease in gene transcription induced by stress, and consequently exert antidepressant-like efficacy. However, intra-nucleus accumbens (NAc) administration of an HDAC inhibitor has also been reported to produce antidepressant-like effects in mice subjected to chronic social defeat stress (Covington et al., 2009). Therefore, both systemic as well as regional administration of HDAC inhibitors exhibits an antidepressant-like efficacy.

\section{Epigenetic discoveries leading to new treatments for major depression}

While numerous rodent studies have revealed alterations in gene expression profiles in the brain in response to stress exposure, it is well recognized that chronic administration of antidepressant drugs leads to alterations in gene expression profiles, and consequently ameliorates the aberrant gene expression that follows stress exposure. Based on these findings, it is conceivable that histone modifications are only one of the key factors involved in the pathophysiology of major depression. Current pharmacotherapies for depression using SSRIs and/or SNRIs have substantial limitations. For example, there is a significant delay between the onset of 
pharmacological action and achievement of a therapeutic response (Rosenzweig-Lipson et al., 2007). In addition, even with appropriate pharmacological treatments, less than $50 \%$ of patients with depression achieve full remission (Little, 2009). It is therefore imperative to develop a new epigenetic drug with a faster onset and greater efficacy in the treatment of major depression.

Several recent rodent studies (Bilang-Bleuel et al., 2005, Chandramohan et al., 2008, Covington et al., 2009, Covington et al., 2011, Ferland and Schrader, 2011, Fuchikami et al., 2009, Hollis et al., 2010, Lin et al., 2012, Renthal et al., 2007, Tsankova et al., 2006, Uchida et al., 2011) have demonstrated that stress exposure and antidepressants affect histone modifications (Table 1). For example, Tsankova and colleagues (2006) showed that down-regulation of HDAC5 was associated with the antidepressant efficacy of imipramine in a social defeat stress paradigm. Sodium butyrate (SB) alone or in combination with fluoxetine was shown to have antidepressant-like effects in the tail suspension test (TST) in mice (Schroeder et al.-, 2007). Similarly, we recently demonstrated that repeated administration of SB significantly reduced immobility on the forced swimming test (FST) and the TST (Yamawaki et al., 2012). These findings suggest that the activity of HDACs might be involved in the therapeutic actions of antidepressants. 
A series of studies conducted by Nestler and colleagues (Covington et al., 2009,

Renthal et al., 2007) revealed that the levels of acetylated histone H3 were persistently increased in the NAc after chronic social defeat stress, and this effect was accompanied by decreased levels of HDAC2 in the NAc. Infusion of MS-275 (a specific class I HDAC inhibitor) into the NAc after stress had antidepressant-like effects in several behavioral tests. Moreover, global patterns of gene expression in the NAc after MS-275 infusion showed fluoxetine-like gene expression profiles. Uchida and colleagues (2011) reported that chronic ultra-mild stress enhanced the mRNA levels of HDAC2 in the NAc of BALB/c mice, and the enhancement was reversed by infusion of imipramine. Furthermore, BALB/c mice overexpressing dominant-negative HDAC2 in the NAc showed increased social interaction times and greater sucrose preference compared with controls. Renthal and co-workers (2007) found that chronic social defeat stress down-regulated HDAC5 mRNA in the NAc, whereas chronic treatment with imipramine alleviated the down-regulation of HDAC5 mRNA. Moreover, HDAC5-knockout mice exhibited more severe social avoidance after chronic social defeat stress as compared with controls. In contrast to the findings in the NAc, chronic social defeat stress caused a persistent decrease in the levels of acetylated histone $\mathrm{H} 3$ in the hippocampus (Covington et al., 2011). This change was reversed by chronic 
systemic administration of fluoxetine and intra-hippocampal infusion of MS-275.

Infusion of MS-275 into the hippocampus increased sucrose preference after chronic social defeat stress, but it did not ameliorate stress-induced social avoidance. Taken together, these findings support the antidepressant potential of HDAC inhibitors and provide new insight into the epigenetic mechanisms of depression and antidepressants.

As shown in Table 1, the NAc and hippocampus are the 2 most studied brain regions in general; however, a limited number of studies of the amygdala (Covington et al.,, 2011, Renthal et al., 2007) and prefrontal cortex (Lin et al., 2012) have been published. For example, Lin and colleagues recently demonstrated that chronic infusion of MS-275 into the ventrolateral orbital cortex (VLO) significantly reduced immobility time in the FST and TST compared with controls, similar to the effects of systemic administration of fluoxetine, and these antidepressant-like effects of MS-275 were associated with an increase in H3 acetylation, CREB, and BDNF in the VLO (Lin et al., 2012). It has been suggested that the orbitofrontal cortex might be involved in the pathogenesis of depression (Drevets, 2007); therefore, further studies are needed to elucidate the involvement of histone modification in this brain region. A summary of the genes and brain regions involved in the antidepressant-like efficacy of HDAC inhibitors is presented in Table 2. 
It would also be helpful to utilize reliable indicators of drug efficacy, if suitable biomarkers can be identified in peripheral blood. One study reported that mRNA levels of HDAC5 and CREB were significantly higher in drug-free depressive patients than in controls, and the higher mRNA levels returned to control levels after treatment with paroxetine (Iga et al., 2007). Another recent study observed that in patients with major depressive disorder, the expression of HDAC2 and HDAC5 was enhanced in a depressive state but not in a remissive state (Hobara et al., 2010). These findings suggest that altered expression of HDAC mRNA in peripheral blood is promising as a biological marker.

If chromatin condensation occurs as a result of stress exposure through the aberrant expression and activity of HDACs, then the binding of transcription factors, such as phospho-CREB, to their binding sites may be impeded even though the levels of transcription factors are increased by chronic antidepressant treatment. If the accessibility of transcription factors to their binding sites is decreased due to chromatin condensation in major depression, the efficacy of antidepressants may fail to be exerted. In this context, the combined administration of an antidepressant and an HDAC inhibitor could be helpful in the treatment of antidepressant-resistant patients with major depression (Figure 1). 


\section{Clinical potential of HDAC inhibitors for the treatment of depression}

To date, no clinical trials have been conducted to evaluate HDAC inhibitors for the treatment of depression; therefore the clinical potential for such therapy in the treatment of patients with depression remains unknown. Based on the results of the clinical trial of vorinostat and romidepsin on refractory cutaneous and peripheral $\mathrm{T}$ cell lymphoma, the U.S. FDA recently approved these HDAC inhibitors for clinical use. In addition, the efficacy and safety of sodium butyrate- and MS-275 have been examined for the treatment of cancer, although the possibility of clinical use of these HDAC inhibitors remains controversial for treatment of cancer. Vorinostat was the first HDAC inhibitor drug to be approved for clinical use by the FDA for the treatment of refractory cutaneous T-cell lymphoma. In line with the efficacy results observed with HDAC inhibitors in rodent models of depression, our previous study demonstrated that administration of vorinostat in conjunction with extinction training of conditioned fear markedly ameliorated impaired fear memory extinction in an animal model of posttraumatic stress disorder (PTSD) (Fujita et al., 2012, Vecsey et al., 2007). In studies of HDAC inhibitors, a key difference observed between animal models of depression and PTSD is the duration of HDAC inhibitor administration required to produce an effect; i.e., in our rat model of PTSD a single administration of vorinostat was effective 
in improving impaired fear extinction. In contrast, in animal studies of depression, HDAC inhibitors had to be administered chronically to produce an antidepressant-like effect, suggesting that long-term administration may be needed in the clinical treatment of depression. The clinical potential of vorinostat is limited by the drug's adverse effects. The most common clinical adverse events of any grade are diarrhea (52\%), fatigue (52\%), nausea (41\%), and anorexia (24\%) (Mann et al.-, 2007). Therefore, in the treatment of depression it may be problematic to use vorinostat chronically as it is in cancer therapy, but not acutely.

\section{Summary and implications}

Almost all studies examining the antidepressant-like efficacy of HDAC inhibitors in rodent models of depression support the clinical potential of using HDAC inhibitors for the treatment of depression. Some studies have shown that administration of HDAC inhibitors augments the effect of antidepressants, suggesting that a combination of antidepressants and HDAC inhibitors could serve as a valuable new treatment for patients with antidepressant-resistant depression. Although the precise mechanism of the antidepressant effects of HDAC inhibitors is unknown, it is conceivable that changes in chromatin structure, such as the initiation of a loose chromatin condition, by 
HDAC inhibitors, may facilitate gene transcription induced by antidepressants. At the present time, vorinostat and romidepsin are the only FDA-approved HDAC inhibitors, both for the treatment of hematologic cancer, but no drugs in this class have been approved for the treatment of depression. Clinical trial evaluations of HDAC inhibitors for the treatment of depression, especially antidepressant-resistant depression, are warranted. The adverse event profiles demonstrated in clinical trials of vorinostat and romidepsin for the treatment of cancer indicate that the use of HDACs for the treatment of depression may be feasible. Since newer HDAC inhibitors with less toxicity have been developed for use in cancer therapy, these drugs may also hold promise for the pharmacotherapy of antidepressant-resistant depression. 


\section{Figure Caption}

Figure 1. If levels of histone acetylation were low during administration of antidepressants, transcription factors, such as phospho-CREB and AP-1, hardly bind to their specific binding sites, and subsequently the transcription rates of various genes are not induced. In contrast, coadministration of antidepressant and HDAC inhibitor can sustain increased levels of histone acetylation, and facilitate the antidepressant-stimulated increase in the transcription rates of various genes. Therefore, it is conceivable that coadministration may enhance the efficacy of antidepressants. AP-1: activator protein 1; BS; binding site; CRE, cAMP response element; CREB, cAMP response element binding protein; $\mathrm{p}-\mathrm{CREB}$; phospho-CREB. 


\section{References}

Ashraf SI, Ip YT. Transcriptional control: Repression by local chromatin modification.

Current Biology 1998;8:R683-6.

Bilang-Bleuel A, Ulbricht S, Chandramohan Y, De Carli S, Droste SK, Reul JM.

Psychological stress increases histone $\mathrm{H} 3$ phosphorylation in adult dentate gyrus

granule neurons: involvement in a glucocorticoid receptor-dependent behavioural

response. The European Journal of Neuroscience. 2005;22:1691-700.

Broide RS, Redwine JM, Aftahi N, Young W, Bloom FE, Winrow CJ. Distribution of

histone deacetylases 1-11 in the rat brain. Journal of Molecular Neuroscience.

2007;31: 47-58.

Chandramohan Y, Droste SK, Arthur JS, Reul JM. The forced swimming-induced

behavioural immobility response involves histone $\mathrm{H} 3$ phospho-acetylation and c-Fos

induction in dentate gyrus granule neurons via activation of the

N-methyl-D-aspartate/extracellular signal-regulated kinase/mitogen- and

stress-activated kinase signalling pathway. The European Journal of Neuroscience.

2008;27:2701-13.

Covington HE, 3rd, Maze I, LaPlant QC, Vialou VF, Ohnishi YN, Berton O, et al.

Antidepressant actions of histone deacetylase inhibitors. The Journal of Neuroscience. 
2009;29:11451-60.

Covington HE, 3rd, Vialou VF, LaPlant Q, Ohnishi YN, Nestler EJ.

Hippocampal-dependent antidepressant-like activity of histone deacetylase inhibition.

Neuroscience Letters. 2011;493:122-6.

Drevets WC. Orbitofrontal cortex function and structure in depression. Annals of the

New York Academy of Sciences. 2007;1121:499-527.

Duman RS, Heninger GR, Nestler EJ. A molecular and cellular theory of depression.

Archives of General Psychiatry. 1997;54:697-706.

Ferland CL, Schrader LA. Regulation of histone acetylation in the hippocampus of chronically stressed rats: a potential role of sirtuins. Neuroscience. 2011;174:104-14.

Fuchikami M, Morinobu S, Kurata A, Yamamoto S, Yamawaki S. Single immobilization stress differentially alters the expression profile of transcripts of the brain-derived neurotrophic factor (BDNF) gene and histone acetylation at its promoters in the rat hippocampus. The International Journal of Neuropsychopharmacology. 2009; 12:73-82.

Fujita Y, Morinobu S, Takei S, Fuchikami M, Matsumoto T, Yamamoto S, et al. Vorinostat, a histone deacetylase inhibitor, facilitates fear extinction and enhances expression of the hippocampal NR2B-containing NMDA receptor gene. Journal of 
Psychiatric Research. 2012;46:635-43.

Gibson, C.L., Murphy, S.P. Benefits of histone deacetylase inhibitors for acute brain injury; a systematic review of animal studies. Journal of . Neurochemistry. 2010;115, 806-13.

Goldberg AD, Allis CD, Bernstein E. Epigenetics: a landscape takes shape. Cell. 2007;128:635-8.

Gräff, J., Tsai, L-H. The potential of HDAC inhibitors as cognitive enhancers. Annual Review of Pharmacology and Toxicology. 2013;53: 311-30.

Grayson DR, Kundakovic M, Sharma RP. Is There a Future for Histone Deacetylase Inhibitors in the Pharmacotherapy of Psychiatric Disorders? Molecular Pharmacology. $2010 ; 77: 126-35$

Greene J, Banasr M, Lee B, Warner-Schmidt J, Duman RS. Vascular endothelial growth factor signaling is required for the behavioral actions of antidepressant treatment: pharmacological and cellular characterization. Neuropsychopharmacology. 2009; 34:2459-68.

Grozinger, C.M., Chao, E.D., Blackwell, H.E., Moazed, D., Schreiber, S.L. Identification of a class of small molecule inhibitors of the sirtuin family of NAD-dependent deacetylases by phenotypic screening. Journal of Biological 
Chemistry. 2001;276, 38837-43.

Han, S-H. Potential role of sirtuin as a therapeutic target for neurodegenerative diseases. Journal of Clinical Neurology. 2009;5: 120-5.

Hisaoka K, Nishida A, Koda T, Miyata M, Zensho H, Morinobu S, Ohta M, Yamawaki

S. Antidepressant drug treatments induce glial cell line-derived neurotrophic factors

(GDNF) synthesis and release in rat C6 glioblastoma cells. Journal of Neurochemistry. 2001;79:25-34

Hobara T, Uchida S, Otsuki K, Matsubara T, Funato H, Matsuo K, et al. Altered gene expression of histone deacetylases in mood disorder patients. Journal of Psychiatric Research. 2010;44:263-70.

Holliday R. Epigenetics: a historical overview. Epigenetics 2006;1:76-80.

Hollis F, Wang H, Dietz D, Gunjan A, Kabbaj M. The effects of repeated social defeat on long-term depressive-like behavior and short-term histone modifications in the hippocampus in male Sprague-Dawley rats. Psychopharmacology. 2010;211:69-77. Iga J, Ueno S, Yamauchi K, Numata S, Kinouchi S, Tayoshi-Shibuya S, et al. Altered HDAC5 and CREB mRNA expressions in the peripheral leukocytes of major depression. Progress in Neuro-Psychopharmacology \& Biological Psychiatry. 2007;31:628-32. 
Khochbin S, Verdel A, Lemercier C, Seigneurin-Berny D. Functional significance of histone deacetylase diversity. Current Opinion in Genetics and Development. 2001;11:162-6.

Kramer $\mathrm{OH}$, Gottlicher M, Heinzel T. Histone deacetylase as a therapeutic target. Trends in Endocrinology and Metabolism. 2001;12:294-300.

Kurdistani SK, Grunstein M. Histone acetylation and deacetylation in yeast. Nature Reviews Molecular Cell Biology. 2003;4:276-84.

Lieb JD, Clarke ND. Control of transcription through intragenic patterns of nucleosome composition. Cell. 2005;123:1187-90.

Lin H, Geng X, Dang W, Wu B, Dai Z, Li Y, et al. Molecular mechanisms associated with the antidepressant effects of the class I histone deacetylase inhibitor MS-275 in the rat ventrolateral orbital cortex. Brain Research. 2012;1447:119-25.

Little A. Treatment-resistant depression. American Family Physician. 2009;80:167-72.

Lopez AD, Mathers CD, Ezzati M, Jamison DT, Murray CJ. Global and regional burden of disease and risk factors, 2001: systematic analysis of population health data. Lancet. 2006;367:1747-57.

Mann BS, Johnson JR, Cohen MH, Justice R, Pazdur R. FDA approval summary: vorinostat for treatment of advanced primary cutaneous T-cell lymphoma. The 
Oncologist. 2007;12:1247-52.

Michishita, E., Park, J.Y., Burneskis, J.M., Barrett, J.C., Horikawa, I. Evolutionarily conserved and nonconserved cellular localizations and functions of human SIRT proteins. Molecular Biology of the Cell 2005;16: 4623-35.

Nestler EJ, Barrot M, DiLeone RJ, Eisch AJ, Gold SJ, et al. Neurobiology of depression. Neuron. 2002;34:13-25.

Phiel CJ, Zhang F, Huang EY, Guenther MG, Lazar MA, Klein PS. Histone deacetylase is a direct target of valproic acid, a potent anticonvulsant, mood stabilizer, and teratogen. Journal of Biological Chemistry. 2001; 276: 36734-41.

Renthal W, Maze I, Krishnan V, Covington HE, 3rd, Xiao G, Kumar A, et al. Histone deacetylase 5 epigenetically controls behavioral adaptations to chronic emotional stimuli. Neuron. 2007;56:517-29.

Rosenzweig-Lipson S, Beyer CE, Hughes ZA, Khawaja X, Rajarao SJ, Malberg JE, et al. Differentiating antidepressants of the future: efficacy and safety. Pharmacology and Therapeutics. 2007;113:134-53.

Rush AJ, Trivedi MH, Stewart JW, Nierenberg AA, Fava M, Kurian BT, et al. Combining medications to enhance depression outcomes (CO-MED): acute and long-term outcomes of a single-blind randomized study. The American Journal of 
Psychiatry. 2011;168:689-701.

Rush AJ, Trivedi MH, Wisniewski SR, Nierenberg AA, Stewart JW, Warden D, et al. Acute and longer-term outcomes in depressed outpatients requiring one or several treatment steps: a STAR*D report. The American Journal of Psychiatry. 2006;163:1905-17.

Schroeder FA, Lin CL, Crusio WE, Akbarian S. Antidepressant-like effects of the histone deacetylase inhibitor, sodium butyrate, in the mouse. Biological Psychiatry. $2007 ; 62: 55-64$

Tsankova NM, Berton O, Renthal W, Kumar A, Neve RL, Nestler EJ. Sustained hippocampal chromatin regulation in a mouse model of depression and antidepressant action. Nature Neuroscience. 2006;9:519-25.

Uchida S, Hara K, Kobayashi A, Otsuki K, Yamagata H, Hobara T, et al. Epigenetic status of Gdnf in the ventral striatum determines susceptibility and adaptation to daily stressful events. Neuron. 2011;69:359-72.

Vecsey CG, Hawk JD, Lattal KM, Stein JM, Fabian SA, Attner MA, et al. Histone deacetylase inhibitors enhance memory and synaptic plasticity via CREB:CBP-dependent transcriptional activation. The Journal of Neuroscience. 2007;27:6128-40. 
Verdin E, Ott M. 50 years of protein acetylation: from gene regulation to epigenetics, metabolism and beyond. Nature Reviews Molecular Cell Biology. 2014. doi: 10.1038/nrm3931. [Epub ahead of priny].

Walkinshaw DR, Yang XJ. Histone deacetylase inhibitors as novel anticancer therapeutics. Current Oncology. 2008;15:237-43.

West AC, Johnstone RW. New and emerging HDAC inhibitors for cancer treatment. Journal of Clinical Investigation. 2014;124:30-9.

Yamawaki Y, Fuchikami M, Morinobu S, Segawa M, Matsumoto T, Yamawaki S. Antidepressant-like effect of sodium butyrate (HDAC inhibitor) and its molecular mechanism of action in the rat hippocampus. The World Journal of Biological Psychiatry. 2012;13:458-67.

Yasuda S, Liang MH, Marinova Z, Yahyavi A, Chuang DM. The mood stabilizers lithium and valproate selectively activate the promoter IV of brain-derived neurotrophic factor in neurons. Molecular Psychiatry. 2009;14:51-9. 
Administration of antidepressant

Hypoacetylation status

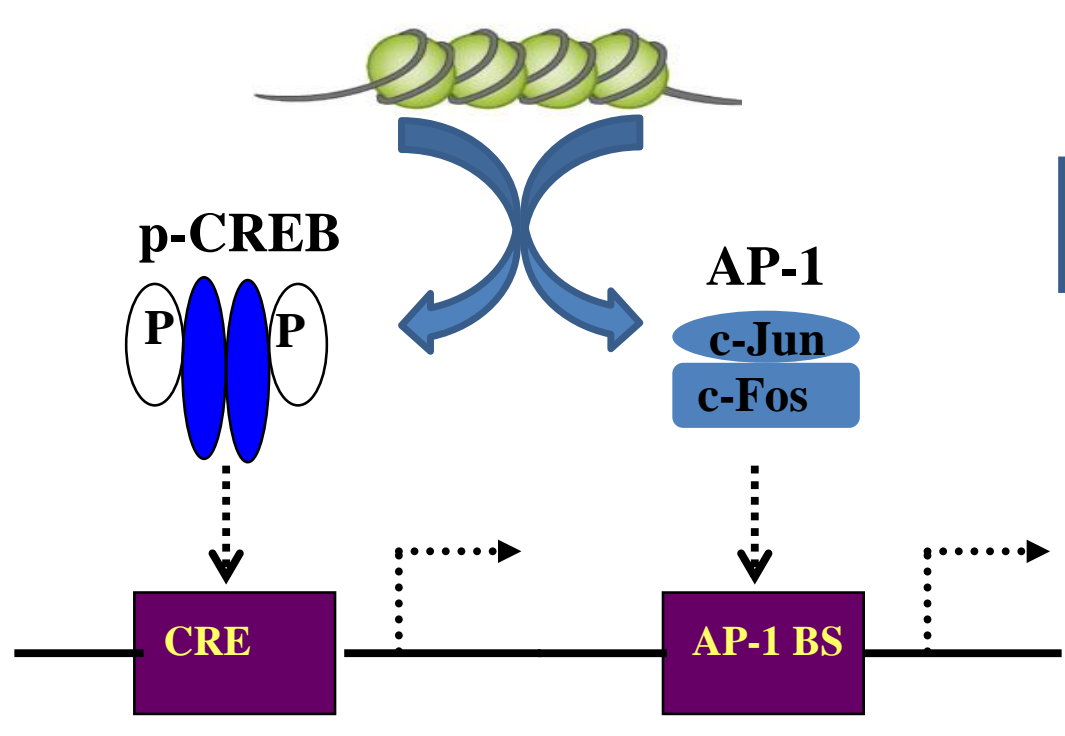

Coadministration of antidepressant and HDAC inhibitor

Hyperacetylation status

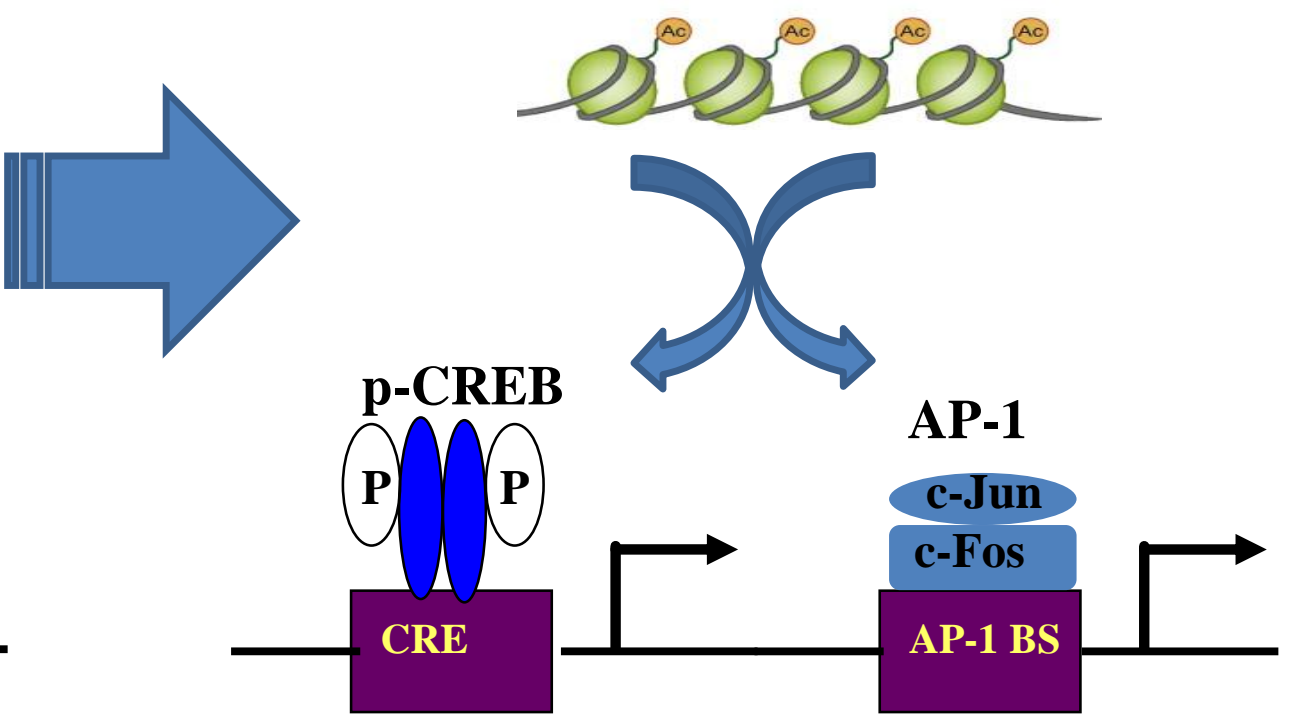


Table 1. Regulation of histone modification and HDAC expression by stress and antidepressants

\begin{tabular}{|c|c|c|}
\hline Treatment & Effect & Reference \\
\hline Social defeat stress & $\begin{array}{l}\text { Increase in acethylated } \mathrm{H3} \text { in the NAc } \\
\text { Decrease in HDAC2 in the Nac }\end{array}$ & $\begin{array}{l}\text { Covington et al. } \\
\text { (2009) }\end{array}$ \\
\hline $\begin{array}{l}\text { Social defeat stress } \\
+ \text { imipramine }\end{array}$ & $\begin{array}{l}\text { Decrease in HDAC5 in the NAc } \\
\text { Imipramine reverses the HDAC5 } \\
\text { expression }\end{array}$ & $\begin{array}{l}\text { Renthal et al. } \\
\text { (2007) }\end{array}$ \\
\hline $\begin{array}{l}\text { Chronic ultra-mild } \\
\text { stress } \\
+ \text { imipramine }\end{array}$ & $\begin{array}{l}\text { Increase in } \mathrm{HDAC} 2 \text { in the NAc } \\
\text { Imipramine reverses the HDAC2 } \\
\text { expression }\end{array}$ & $\begin{array}{l}\text { Uchida et al. } \\
\text { (2011) }\end{array}$ \\
\hline Forced swim stress & $\begin{array}{l}\text { Increase in phospho-acethylated } \mathrm{H3} \text { in } \\
\text { the } \mathrm{Hp}\end{array}$ & $\begin{array}{l}\text { Chandramohan et al. } \\
\text { (2008) }\end{array}$ \\
\hline Forced swim stress & $\begin{array}{l}\text { Increase in phospho-acethylated } \mathrm{H3} \text { in } \\
\text { the } \mathrm{Hp}\end{array}$ & $\begin{array}{l}\text { Bilang-Bleuel et al. } \\
\text { (2005) }\end{array}$ \\
\hline Predator stress & $\begin{array}{l}\text { Increase in phospho-acethylated } \mathrm{H3} \text { in } \\
\text { the } \mathrm{Hp}\end{array}$ & $\begin{array}{l}\text { Bilang-Bleuel et al. } \\
\text { (2005) }\end{array}$ \\
\hline Social defeat stress & $\begin{array}{l}\text { Increase in acethylated } \mathrm{H3} \text { in the } \mathrm{Hp} \\
\text { No change in acethylated } \mathrm{H4} \text { in the } \mathrm{Hp}\end{array}$ & $\begin{array}{l}\text { Hollis et al. } \\
\text { (2010) }\end{array}$ \\
\hline Chronic variable stress & $\begin{array}{l}\text { Decrease in acethylated } \mathrm{H} 4 \text { in the } \mathrm{Hp} \\
\text { Decrease in phospho-acethylated } \mathrm{H3} \text { in } \\
\text { the Hp }\end{array}$ & $\begin{array}{l}\text { Ferland et al. } \\
\text { (2011) }\end{array}$ \\
\hline $\begin{array}{l}\text { Social defeat stress } \\
+ \text { imipramine }\end{array}$ & $\begin{array}{l}\text { Decrease in acethylated } \mathrm{H} 3 \text { in the } \mathrm{Hp} \\
\text { Imipramine reverses this change }\end{array}$ & $\begin{array}{l}\text { Covington et al. } \\
\text { (2011) }\end{array}$ \\
\hline $\begin{array}{l}\text { Single immobilization } \\
\text { stress }\end{array}$ & $\begin{array}{l}\text { Decrease in acethylated } \mathrm{H3} \text { at the } \\
\text { promoters of exon } 1,4,6(\mathrm{BDNF}) \text { in the } \\
\text { Hp }\end{array}$ & $\begin{array}{l}\text { Fuchikami et al. } \\
\text { (2009) }\end{array}$ \\
\hline $\begin{array}{l}\text { Social defeat stress } \\
+ \text { imipramine }\end{array}$ & $\begin{array}{l}\text { Increase in } \mathrm{HDAC5} \text { in the } \mathrm{Hp} \\
\text { Imipramine reverses this change }\end{array}$ & $\begin{array}{l}\text { Tsankove et al. } \\
\text { (2006) }\end{array}$ \\
\hline
\end{tabular}

NAc, nucleus accumbens; Hp, hippocampus. 
Table 2. Involvement of brain regions and genes in the antidepressant-like effect of HDAC inhibitors

\begin{tabular}{|llll}
\hline Study & HDAC Inhibitor & Brain Region & Gene \\
\hline Lin et al. (2012) & MS-275 & Ventrolateral Orbital Cortex & CREB, BDNF \\
\hline Han et al. (2014) & Sodium Butyrate & Hippocampus & BDNF \\
\hline Schroeder et al. (2007) & Sodium Butyrate & Frontal Cortex & BDNF \\
\hline Uchida et al. (2011) & Vorinostat & Ventral Striatum & \\
\hline Schmauss (2015) & Trichostatine A & Forebrain Neocortex & BDNF \\
\hline Yamawaki et al. (2012) & Sodium Butyrate & Hippocampus & Transthyretin, 5-HT2A \\
\hline Covington et al. (2009) & MS-275 & Nucleus Accumbens & Cort, Gja5, Adra1a \\
\hline
\end{tabular}

CRS: chronic restraint stress, CSD: chronic social defeat

CREB: cAMP response element binding protein, 5-HT2A: serotonin 2A receptor, Cort: cortistatin, Gja5: gap junction protein $\alpha 5$, Adra1a: adrenergic $\alpha 1 \mathrm{~A}$ receptor 